\title{
Red Fox on the Increase?
}

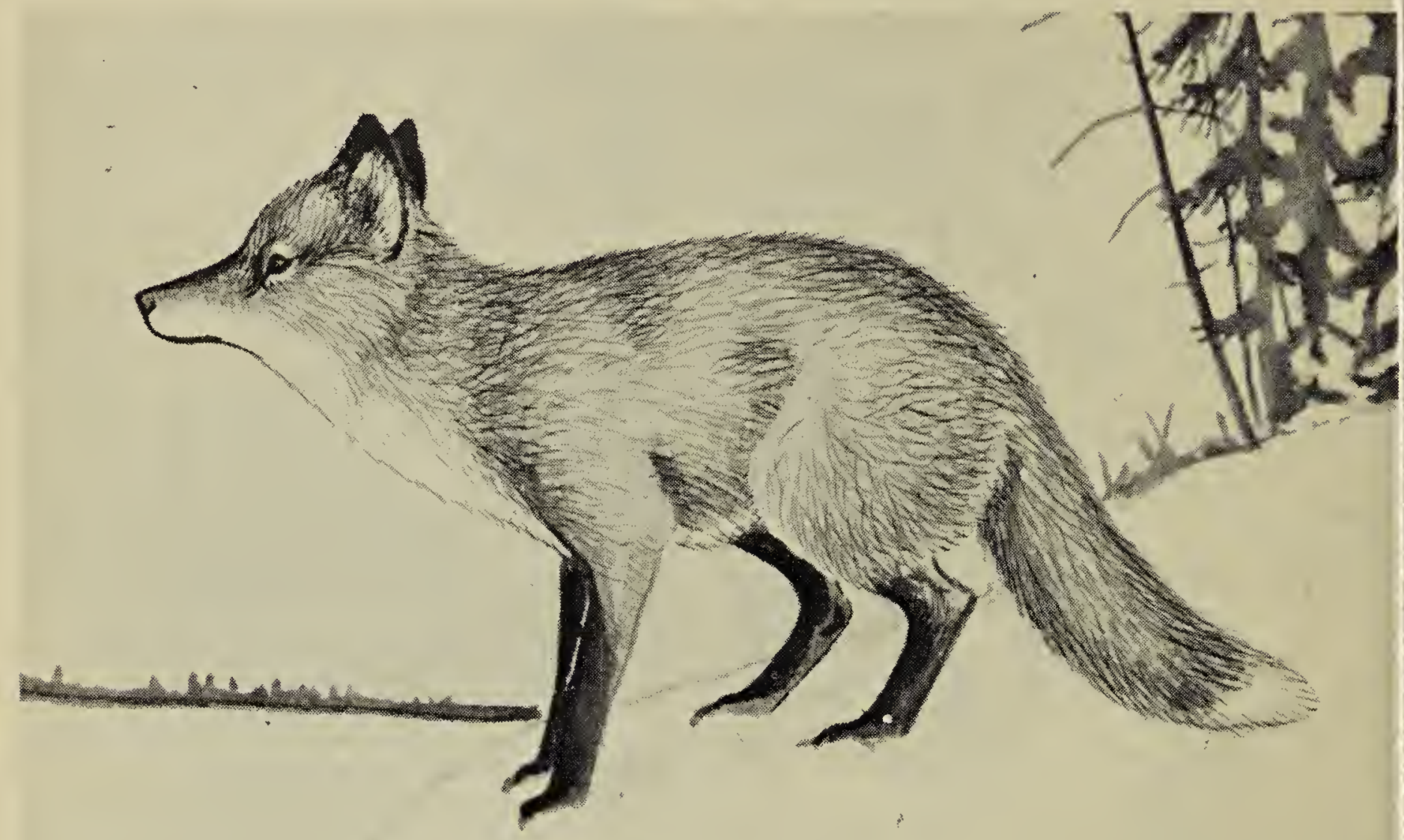

\section{Cax-and}

Sketch of red fox by Richard W. Sutton, Direstor, Manitoba Natural Histci:y Museum.

This little drawing, which was made several years ago, was recently submitted to the Blue Jay through the courtesy of Fred. G. Bard, Director, Saskatchewan Museum of Natural History. Mr. Bard has indicated to us that several reports of high numbers of red foxes have come to his attention. In the months of December, 1962, and January, 1963 , at least 150 have been shot. At Rowatt, seven miles scuth of Regina, 26 were taken in and around the J. Baker farm. Another report comes from the vicinity of Avonlea where 50 were taken. A single silver fox was among the reds.
We feel, along with Mr. Bard, that there is a need for more comprehensive reports of the changing status of cur wildlife species. We hope that resconsible authorities will provide further information on the red fox lynx (there have been casual reports of this northern species in the prairie region), and the much maligned bobcat. The latter species is still unfortunately not even afforded the protection cf a game species. We wonder how much longer we should allow this interesting mammal to be classed, along with rats and house sparrows, as vermin?-ED. NOTE.

\section{Cougars In Saskatchewan}

\section{by Tom White, Regina}

Occasional records of the mountain lion or cougar in Saskatchewan have generally been believed to be of wanderers from the Rockies. How- ever, evidence coming to light in recent years suggests to me that cougars may cccur as residents within the province. This may seem unlikely to 